\title{
Ensino de matrizes: mapeamento de pesquisas acadêmicas que apresentam contextualização no Ensino Médio
}

\author{
Teaching of Matrices: mapping of academic research that presents \\ contextualization in high school
}

\author{
Maria do Socorro Silva Bezerra (profe-socorro@ hotmail.com) \\ Universidade Estadual de Santa Cruz (UESC)
}

Zulma Elizabete de Freitas Madruga (betemadruga@ufrb.edu.br) Universidade Federal do Recôncavo da Bahia (UFRB)

\begin{abstract}
Resumo: Este artigo objetiva analisar como as pesquisas em ensino de Matemática apresentam a contextualização do conteúdo de Matrizes para estimular a aprendizagem de estudantes no Ensino Médio. Trata-se de uma pesquisa qualitativa, na qual foi realizado um mapeamento, utilizando-se para a busca a expressão exata "Ensino de Matrizes" nas seguintes bases de dados: portal de teses e dissertações da Coordenação de Aperfeiçoamento do Pessoal de Nível Superior - (CAPES) e na Biblioteca Digital Brasileira de Teses e dissertações (BDTD). Na análise dos dados, esses trabalhos foram considerados a partir de quatro categorias a priori. Os resultados obtidos mostraram que ao utilizar a contextualização do Ensino de Matrizes nas aulas de Matemática, em seus diferentes entendimentos, seja de forma explícita ou implícita, utilizam-se de três contextos distintos: da realidade, da semi-realidade e da matemática pura.
\end{abstract}

Palavras-chave: Ensino de Matemática; Matrizes; Contextualização; Mapeamento.

Abstract: This article aims to analyze how research in the teaching of Mathematics presents the contextualization of the content of Matrices to stimulate students learning in high school. It is a qualitative research, in which a mapping was carried out, using the exact expression "Teaching of Matrices" in the following databases: search portal for theses and dissertations of the Coordination for the Improvement of Higher Education Personnel - (CAPES) and the Brazilian Digital Library of Theses and Dissertations (BDTD). In analyzing the data, these works were considered from four categories a priori. The results obtained showed that when using the contextualization of Matrix Teaching in Mathematics classes, in their different understandings, either explicitly or implicitly, they use three different contexts: reality, semi-reality and pure mathematics.

Keywords: Mathematics teaching; Matrice; Contextualization; Mapping.

\section{PRIMEIRAS CONSIDERAÇÕES}

O ensino de Matemática, muitas vezes, apresenta-se de maneira descontextualizada (FERNANDES, 2006), o que pode não favorecer o aprendizado do 
estudante, dificultando o processo de ensino e de aprendizagem. Sobre esse olhar, entende-se que ao se contextualizar o conteúdo de Matrizes, o mesmo pode se mostrar mais aplicável à realidade, o que poderá possibilitar maior compreensão por parte dos estudantes.

Conforme a Base Nacional Comum Curricular - BNCC, “[...] um dos desafios para a aprendizagem da Matemática no Ensino Médio é exatamente proporcionar aos estudantes a visão de que ela não é um conjunto de regras e técnicas, mas faz parte de nossa cultura e de nossa história" (BRASIL, 2018, p. 522). As Orientações Curriculares Nacionais para o Ensino Médio caracterizam-no como uma etapa que deve preparar os estudantes para a compreensão do mundo e para a resolução de problemas do cotidiano, valorizando a contextualização em sala de aula.

É na dinâmica de contextualização/descontextualização que o aluno constrói conhecimento com significado, nisso se identificando com as situações que lhe são apresentadas, seja em seu contexto escolar, seja no exercício de sua plena cidadania. [...] a contextualização aparece não como uma forma de "ilustrar" o enunciado de um problema, mas como uma maneira de dar sentido ao conhecimento matemático na escola (BRASIL, 2006, p. 83).

Por meio da contextualização, pode-se mostrar, por exemplo, a inserção das Matrizes no cotidiano dos estudantes, servindo como ferramenta prática no processo de ensino e de aprendizagem. É importante levar o estudante a construir o seu conhecimento, instigando-o a perceber a utilidade e importância de cálculos matriciais, tornando assim, o conteúdo de Matrizes mais próximo de sua realidade, relacionando-o com situações vivenciadas por eles frequentemente.

Nesse sentido, a seguinte questão instigou a realização deste estudo: como as pesquisas em ensino de Matemática apresentam a contextualização do conteúdo de Matrizes para estimular a aprendizagem de estudantes do Ensino Médio? A partir desta indagação, foi traçado o seguinte objetivo: analisar como as pesquisas em ensino de Matemática apresentam a contextualização do conteúdo de Matrizes para estimular a aprendizagem de estudante no Ensino Médio.

\section{TENTATIVAS DE COMPREENDER A CONTEXTUALIZAÇÃO}

A ideia de contextualização é muito abstrata, e divergente para alguns autores. Para compreender melhor o significado deste conceito é necessário esclarecer que ele é entendido normalmente por contexto. De acordo com Skovsmose (2000) as atividades 
escolares podem fazer parte de três contextos distintos: a) matemática pura - quando determinada situação pertence integralmente à matemática acadêmica; b) semirealidade - quanto tratam-se de situações fictícias, mas que envolvem elementos do cotidiano (realidade construída), podendo servir como suporte para os estudantes na resolução de problemas; c) realidade - quando descreve situações ocorridas na vida científica ou diária. Não há uma distinção clara entre esses contextos, e o autor argumenta que é necessário "reconhecer a enorme diversidade de contextos em que a matemática pode ser trazida em operação, bem como desafiar as aplicações da matemática e automaticamente o envolvimento de qualidades atraentes destas" (SKOVSMOSE, 2017, p. $33)$.

No entendimento das autoras desta pesquisa, conhecer o contexto significa ter melhores condições de se apropriar de um dado conhecimento, de uma informação. É o conjunto de circunstâncias em que se produz a mensagem que se deseja emitir, portanto contextualizar é o ato pelo qual se leva em conta o contexto de uma situação, acontecimento ou fato, preferencialmente em relação à realidade. Skovsmose (2000, p.1) salienta que "mover-se da referência à matemática pura para a referência a vida real pode resultar em reflexões sobre a matemática e suas aplicações". É importante ressaltar que o significado da ideia de contextualização é passível de muitas interpretações, requer cuidado pois se trata de um tema que pode ser apresentado sob diversos enfoques.

Segundo Kato (2007), é muito comum questionamentos sobre as interpretações da ideia de contextualização feitas por professores e educadores, justamente pelo fato de que existem vários significados para o termo na área educacional, por exemplo, segundo Ferreira (1992), contextualizar significa interpretar ou analisar, tendo em conta o contexto em que está inserido, enquanto que para Tufano (2001, p. 41), "a contextualização é um ato particular. Cada autor, escritor, pesquisador ou professor contextualiza de acordo com suas origens, com suas raízes, com seu modo de ver as coisas com muita prudência". Neste sentido, a contextualização fica condicionada às mudanças de atitudes diante da problematização de um conhecimento.

No que tange à contextualização no ensino de matemática, corrobora-se com a tese de Maioli (2012, p. 31) na qual afirma que "a contextualização é um princípio pedagógico potencialmente rico para melhorar a aprendizagem de matemática dos 
alunos, mas precisa ser compreendida em seus propósitos e usos pelos diferentes atores do processo de ensino e aprendizagem".

No caso onde a realidade é a referência, é necessário considerar as vivências cotidianas dos estudantes que estão envolvidos em diferentes condições socioeconômicas e culturais. A contextualização pode se constituir como uma maneira de tornar a aprendizagem com mais significado, pois é possível motivar os estudantes a relacionarem o que está sendo estudado com suas experiências do dia-a-dia, estimulando o raciocínio, a criatividade e a curiosidade dos mesmos.

No entanto, cabe destacar que

Estar descontextualizado, a nosso entender, não significa que não esteja associado a alguma experiência do cotidiano. Significa que o conceito não foi compreendido no ambiente de ocorrência, no caso, no ambiente matemático. O aluno traz uma bagagem cognitiva que, como diz Koch (2003), já é um contexto. Talvez pudéssemos dizer que estar descontextualizado seria não estar ajustado ao contexto considerado, em nosso caso, ao contexto matemático (MAIOLI, 2012, p. 51).

Talvez uma maneira de contextualizar os conteúdos de matemática em contextos que considerem a realidade, seja por meio da modelagem matemática. Para Barbosa (2004) a modelagem matemática é uma atividade que convida os estudantes para a discussão da matemática no contexto de situações cotidianas e/ou da realidade. "Não se trata, portanto, de contextualizar a matemática, mas de discuti-la à luz de um contexto que não é o da área específica" (BARBOSA, 2004, p. 3).

Bassanezi (2010, p. 16) afirma que "a Modelagem Matemática consiste na arte de transformar problemas da realidade em problemas matemáticos e resolvê-los interpretando suas soluções na linguagem do mundo real". Conforme as ideias deste autor, os modelos são construídos a partir de situações contextualizadas da realidade.

Bassanezi (2010), define modelagem como um método de pesquisa que consiste em trazer problemas da realidade para os espaços escolares, transformá-los em modelos (matemáticos) e devolver para a realidade. A modelagem pode ser considerada uma proposta de solucionar problemas relacionados ao cotidiano, comprometida não apenas com o conteúdo matemático a ser transmitido, mas também com as mais distintas situações da vivência do ser humano.

Para ilustrar esse processo de tomar a realidade como referências, criar modelos e devolvê-los para a realidade, apresenta-se na Figura 1 um esquema sobre 
contextualização proposto por Ricardo (2005, p. 239), onde o autor mostra duas curvas distintas:

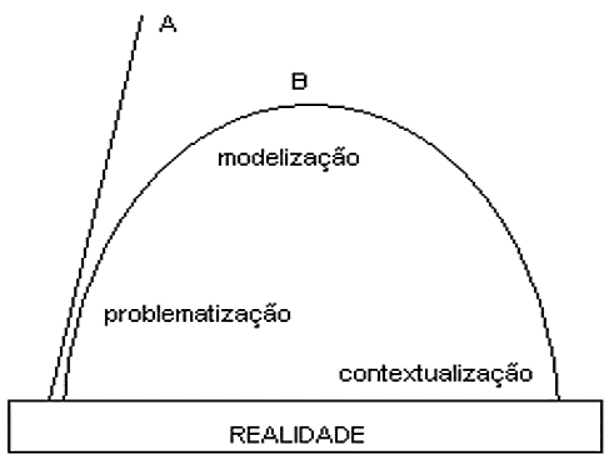

Figura 1 - Esquema ilustrativo que mostra uma compreensão sobre a contextualização

A situação A exibida no esquema de Ricardo (2005), mostra uma compreensão sobre a contextualização, na qual os problemas propostos em sala de aula mostram a Matemática a partir de exemplos da realidade ou semi-realidade (SKOVSMOSE, 2000), fazendo com que a aprendizagem fique restrita ao desenvolvimento de procedimentos, ou seja, às questões internas da Matemática. O fim é o conhecimento sistematizado em situações didáticas excessivamente artificiais, relacionados à matemática pura, que têm sentido no interior da própria escola. A situação inversa, na qual parte-se do abstrato da matemática e a aplica a realidade, também reforça o desenvolvimento de procedimentos matemáticos com fins em si mesmo. No entanto,

A curva B exige um retorno à realidade [...] A contextualização, nesse caso, completa-se no momento em que se parte da realidade e a ela retorna, mas com um novo olhar, com possibilidades de compreensão e ação, pois agora se dispõe de ferramentas intelectuais para tal. (RICARDO, 2005, p. 239).

A contextualização acontece no momento em que se retorna a essa realidade sucede a problematização e a modelização. É na etapa que o autor chama de modelização que os saberes a ensinar serão trabalhados.

Assim como Ricardo (2005), compreende-se que a contextualização exige um movimento maior, em que o professor precisa além de partir de uma realidade, retornar à realidade. Cabe ao professor utilizar uma estratégia de ensino que auxilie a aprendizagem dos estudantes, atribuindo sentido a determinados assuntos.

Para Conceição, Jesus e Madruga (2018, p. 306), no que tange à contextualização, 
[...] propor um ensino que venha favorecer a aprendizagem da Matemática pelo estudante não é uma tarefa fácil, requer mudança e/ou ampliação das concepções acerca dessa temática, visto que, muitas vezes, incorpora-se esse tema no discurso sem entender o seu real significado na prática em sala de aula, o que pode implicar em dificuldades para a aprendizagem.

Em consonância com as ideias de Maioli (2012), é necessário que o estudante esteja imerso ao contexto considerado pelo professor. Pois muitas vezes, considera-se o contexto da matemática pura, da semi-realidade ou de uma realidade externa que não faz parte da vida dos estudantes, ignorando se o estudante ao qual se pretende ensinar se sente parte integrante das circunstâncias ou contexto no qual a aprendizagem deveria ocorrer.

A seguir, apresentam-se os caminhos metodológicos da pesquisa, na qual enfoca a busca de pesquisas que tratem da contextualização no ensino de matrizes.

\title{
3. CAMINHOS METODOLÓGICOS DA PESQUISA
}

Essa pesquisa é de cunho qualitativo, em consonância com Bogdan e Biklen (2010), onde foi feita uma busca bibliográfica sobre tema 'Ensino de Matrizes', nas bases de dados da Coordenação de Aperfeiçoamento de Pessoal de Nível Superior (CAPES) e na Biblioteca Digital Brasileira de Teses e Dissertações (BDTD), sob o enfoque do Mapeamento da Pesquisa Educacional (BIEMBENGUT, 2008). O mapeamento permite organizar documentos e informações para efetuar análise dos dados, levando em conta o que for relevante sobre a temática escolhida. Segundo Biembengut (2008, p. 74),

\begin{abstract}
Mapeamento é um conjunto de ações que começa com a identificação dos entes ou dados envolvidos com o problema a ser pesquisado, para, a seguir, levantar, classificar e organizar tais dados de forma a tornarem mais aparentes as questões a serem avaliadas, reconhecer padrões, evidências, traços comuns ou peculiares, ou ainda características indicadoras de relações genéricas, tendo como referência o espaço geográfico, o tempo, a história, a cultura, os valores, as crenças e as ideias dos entes envolvidos.
\end{abstract}

Para organizar os documentos analisados nessa pesquisa realizou-se no portal da CAPES uma busca com a palavra-chave "Matrizes" onde foram encontradas 12.778 pesquisas, todas armazenados em 639 páginas e abrangendo várias áreas do conhecimento.

Devido ao grande número de pesquisas encontradas, foram utilizados filtros para reduzir o número de pesquisas a serem analisadas. $O$ primeiro filtro disponível na página é denominado como "tipo", quais 8.079 eram dissertações e 3.957 teses, 
aplicando esse filtro tem-se um total de 12.036 pesquisas. $\mathrm{O}$ filtro seguinte foi "grande área de conhecimento": Ciências Exatas e da Terra, totalizando 2.536 trabalhos. No filtro "área de conhecimento" foi selecionado Matemática, resultando em 170 trabalhos. O filtro "nome do programa" tem-se a opção de selecionar o nome do programa dos quais os trabalhos estão relacionados. Nesta pesquisa, as opções selecionadas foram: Matemática, Matemática aplicada e Matemática e computação científica tendo como resultado 163 pesquisas.

Após uma filtragem das 163 pesquisas encontradas foi realizada a leitura dos títulos e resumos de cada um deles, os quais ainda eram muito abrangente visto que o termo 'Matrizes' é amplo e abrange várias áreas da Matemática, tais como por exemplo: Problema dos Mínimos Quadrados com Matrizes Esparsas; Identidades Polinomiais Graduadas de Matrizes Triangulares; Sistemas dinâmicos que triangularizam matrizes; optou-se então por pesquisar no banco de dados da CAPES uma nova palavra-chave "Ensino de Matrizes" tendo como resultados 40 pesquisas, devido ao número restrito, não foi necessário aplicar filtros, optando por fazer uma análise preliminar de todos os trabalhos.

Das 40 pesquisas selecionadas, foram analisados os seus títulos, resumo, objetivo/problema, palavras-chave e justificativa de cada uma, sendo que a contextualização serviu como base teórica para a análise das pesquisas selecionadas. Nesse sentido, as pesquisas que abrangiam aplicações, situações problemas e explicitamente a contextualização, foram selecionadas para o corpus de análise. Sendo excluídas as pesquisas que tratavam sobre TIC, inclusão, enfoque geométrico, criptografia, softwares e jogos, os quais totalizaram 30 pesquisas, tendo então como resultado final para análise, 10 trabalhos da base de dados da CAPES.

Utilizando-se da Biblioteca Digital Brasileira de Teses e dissertações (BDTD) para uma nova busca e ainda aplicando a palavra-chave "Ensino de matrizes" teve-se como resultado 23 trabalhos entre eles tese e dissertações, armazenados em duas páginas sendo a primeira com 20 trabalhos e a segunda com os três últimos. Desses 23 trabalhos foram analisados seus títulos, resumo, objetivo/problemas, palavras-chaves e justificativas. Observando então que nove não abordavam o tema Ensino de Matrizes, 10 são idênticas às já encontradas no banco de dados da CAPES e duas pesquisa estão armazenada com o mesmo título Planilha eletrônica Excel e a matemática: Desenvolvimento de aplicativo para o ensino de matriz, esse trabalho não foi analisado 
por que com o endereço - $\operatorname{link}^{1}$ não foi possível acessar o trabalho. Resultando então dois trabalhos que farão parte desta pesquisa.

A partir do mapeamento realizado nos bancos de dados da CAPES e da BDTD obtiveram-se 12 trabalhos, todas dissertações e nomeadas de A1 até A12. Apresentamse a seguir o Quadro 1, onde constam as pesquisas analisadas.

Quadro 1- Principais pesquisas encontradas no banco de dados da CAPES e da BDTD.

\begin{tabular}{|c|c|c|}
\hline Identificação & Referência & $\begin{array}{l}\text { Banco de } \\
\text { Dados }\end{array}$ \\
\hline A1 & $\begin{array}{l}\text { MEDICO, L.D. O ensino-aprendizagem de matrizes e determinantes por meio de } \\
\text { resolução de problemas. Dissertação. Centro Universitário Franciscano, Santa Maria, } \\
2008 \text {. }\end{array}$ & CAPES \\
\hline A2 & $\begin{array}{l}\text { BRANDÃO, P.C.S. Estudo de matrizes de maneira significativa. Dissertação. } \\
\text { Universidade Federal de Mato Grosso do Sul, Três Lagoas, } 2018 .\end{array}$ & CAPES \\
\hline A3 & $\begin{array}{l}\text { MESQUITA, B. N. Contextualização do Ensino de Matrizes como ferramenta } \\
\text { motivadora. Dissertação. Universidade Estadual de Alagoas, Maceió, } 2017 .\end{array}$ & CAPES \\
\hline A4 & $\begin{array}{l}\text { SOUZA, S.L.A. O Ensino de Matrizes Utilizando Teoria dos Grafos. Dissertação. } \\
\text { Universidade Federal de Mato Grosso. Barra do Garças, } 2017 .\end{array}$ & CAPES \\
\hline A5 & $\begin{array}{l}\text { SILVA, H. C. M. O ensino de matrizes a partir da resolução de problemas. } \\
\text { Dissertação. Universidade do Estado do Pará, Belém, } 2016 \text {. }\end{array}$ & CAPES \\
\hline A6 & $\begin{array}{l}\text { FILHO, A. J. S. Aplicações e resoluções de problemas como metodologia para o } \\
\text { ensino de Matrizes, Sistemas Lineares e Determinantes. Dissertação. Universidade } \\
\text { Federal do Piauí, Teresina, 2013. }\end{array}$ & CAPES \\
\hline A7 & $\begin{array}{l}\text { TRINDADE, J. R. Uma proposta de sequência didática para o ensino de matrizes no } \\
\text { ensino médio. Dissertação. Universidade Federal do Espírito Santo, Vitória, } 2017 .\end{array}$ & CAPES \\
\hline A8 & $\begin{array}{l}\text { FONSECA, M. A. M. O uso da planilha e correio eletrônico como recursos didáticos } \\
\text { no ensino de matrizes, determinantes e sistemas lineares: uma experiência com alunos } \\
\text { do Ensino médio. Dissertação. Universidade Estadual do Sudoeste da Bahia, Vitoria } \\
\text { da Conquista, 2013. }\end{array}$ & CAPES \\
\hline A9 & $\begin{array}{l}\text { SCHÜRMANN, H. A. Criptografia matricial aplicada ao ensino médio. Dissertação. } \\
\text { Universidade Estadual de Londrina, Londrina, } 2013 .\end{array}$ & CAPES \\
\hline A10 & $\begin{array}{l}\text { JÚNIOR, L. F. O. A contextualização de matrizes no ensino médio: uma proposta de } \\
\text { trabalho. Dissertação. Universidade Federal do Tocantins, Palmas, } 2014 .\end{array}$ & CAPES \\
\hline A11 & $\begin{array}{l}\text { BARRIOS, J. C. Modelagem matemática: Uma abordagem do método gráfico e do } \\
\text { método simplex na resolução de problemas de otimização. Dissertação. Faculdade de } \\
\text { Ciências e Tecnologia da Universidade Estadual Paulista "Júlio de Mesquita Filho", } \\
\text { Presidente prudente, } 2015 \text {. }\end{array}$ & BDTD \\
\hline A12 & $\begin{array}{l}\text { REIS, M. S. O ensino e aprendizagem de matrizes no contexto da resolução de } \\
\text { problemas e da plataforma whatsapp. Dissertação. Universidade Federal do Pará, } \\
\text { Belém, 2017. }\end{array}$ & BDTD \\
\hline
\end{tabular}

Os trabalhos analisados de uma maneira geral, trazem uma abordagem de investigação qualitativa, com foco principal em contextualização de Matrizes no que tange o processo de ensino e aprendizagem da Matemática, em uma tentativa de proporcionar eficácia no processo educacional do estudante.

\section{ANÁLISE DOS DADOS}

\footnotetext{
${ }^{1}$ Disponível em http://tede.bc.uepb.edu.br/tede/jspui/handle/tede/1981. Acesso em 22 de maio de 2019.
}

Recebido em: 09.09.2019

Aceito em: 26.06.2020 
Para análise das pesquisas, foram estabelecidas quatro categorias a priori, inspiradas em Madruga e Breda (2017), bem como nas leituras prévias das pesquisas. Dessa forma, optou-se por analisar em cada pesquisa os seguintes aspectos: a) Objetivo(s); b) Bases teóricas; c) Principais resultados; d) Indícios de contextualização de Matrizes. Apresentam-se a seguir cada uma das categorias elencadas.

\section{a) Objetivo(s)}

Nesta subseção são apresentados os objetivos das pesquisas obtidas durante o mapeamento realizado (conforme Quadro 1). Para isso retomaram-se as referidas pesquisas, organizando-as no Quadro 2 (a seguir), contendo: identificação, título e objetivo de cada uma. Em seguida analisou-se cada objetivo visando realizar um estudo comparativo dentre elas, com ênfase na busca por indícios de contextualização.

Pois de acordo com Marconi e Lakatos (2003), toda pesquisa deve ter um objetivo determinado para saber o que se vai procurar e o que se pretende alcançar. A questão de pesquisa e o objetivo devem estar de alguma forma relacionados e representam o rumo da investigação.

Quadro 2 - Objetivos das dissertações analisadas.

\begin{tabular}{|c|c|c|}
\hline Identificação & Titulo & Objetivo \\
\hline A1 & $\begin{array}{l}\text { O ensino-aprendizagem } \\
\text { matrizes e determinantes } \\
\text { meio por } \\
\text { problemas. }\end{array}$ & $\begin{array}{l}\text { Analisar as possibilidades que a resolução de problemas com } \\
\text { matrizes e determinantes podem oferecer para uma aprendizagem } \\
\text { significativa de conceitos matemáticos. }\end{array}$ \\
\hline 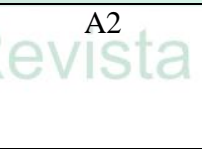 & $\begin{array}{l}\text { Estudo de matrizes de maneira } \\
\text { significativa. }\end{array}$ & $\begin{array}{l}\text { Refletir sobre o ensino de matrizes, fazendo uma introdução } \\
\text { teórica sobre conceitos que fazem parte do conteúdo abordado no } \\
\text { ensino médio, para em seguida analisar livros didáticos e a forma } \\
\text { como abordam esse conteúdo. }\end{array}$ \\
\hline A3 & $\begin{array}{l}\text { Contextualização do Ensino de } \\
\text { Matrizes como ferramenta } \\
\text { motivadora. }\end{array}$ & $\begin{array}{l}\text { Ressaltar a importância do emprego das ferramentas de } \\
\text { sensoriamento remoto e de processamento digital de imagens no } \\
\text { processo de ensino-aprendizagem de matrizes com emprego do } \\
\text { software MatLab. }\end{array}$ \\
\hline A4 & $\begin{array}{l}\mathrm{O} \text { ensino de matrizes utilizando } \\
\text { teoria dos grafos. }\end{array}$ & $\begin{array}{l}\text { Introduzir e apresentar o ensino de matrizes utilizando teoria dos } \\
\text { grafos de forma contextualizada, usando argumentos geométricos } \\
\text { e algébricos. }\end{array}$ \\
\hline A5 & $\begin{array}{l}\mathrm{O} \text { ensino de matrizes a partir da } \\
\text { resolução de problemas. }\end{array}$ & $\begin{array}{l}\text { Avaliar a potencialidade de uma sequência didática baseada na } \\
\text { utilização da resolução de problemas como ponto de partida no } \\
\text { ensino de matrizes. }\end{array}$ \\
\hline A6 & $\begin{array}{l}\text { Aplicações e resoluções de } \\
\text { problemas como metodologia } \\
\text { para o ensino de matrizes, } \\
\text { sistemas lineares e } \\
\text { determinantes. }\end{array}$ & $\begin{array}{l}\text { Apresentar os conteúdos de matrizes, sistemas lineares e } \\
\text { determinantes aos professores de Matemática do Ensino Médio, } \\
\text { dando ênfase às situações problemas e aplicações que } \\
\text { relacionamos conteúdos com situações práticas do dia a dia ou } \\
\text { com aplicações, como uma opção de metodologia de ensino. }\end{array}$ \\
\hline A7 & $\begin{array}{l}\text { Uma proposta de sequência } \\
\text { didática para o ensino de } \\
\text { matrizes no ensino médio. }\end{array}$ & $\begin{array}{l}\text { Desenvolver a prática matemática apresentando o tema matrizes } \\
\text { de modo tal que o aluno desenvolva o saber matemático e } \\
\text { consiga responder aquela pergunta pragmática: "pra quê se } \\
\text { aprende isto?" }\end{array}$ \\
\hline A8 & $\begin{array}{l}\text { O uso da planilha e correio } \\
\text { eletrônico como recursos } \\
\text { didáticos no ensino de matrizes, } \\
\text { determinantes e sistemas } \\
\text { lineares: uma experiência com }\end{array}$ & $\begin{array}{l}\text { Investigar as possíveis contribuições que o uso das planilhas } \\
\text { eletrônicas como recurso didático podem oferecer no estudo e } \\
\text { entendimento dos conteúdos de matrizes, determinantes e } \\
\text { sistemas lineares, com alunos do } 2^{\circ} \text { ano do Ensino Médio, através } \\
\text { da resolução de situações problemas. }\end{array}$ \\
\hline
\end{tabular}




\begin{tabular}{|l|l|l|}
\hline & alunos do ensino médio. & \\
\hline A9 & $\begin{array}{l}\text { Criptografia matricial aplicada } \\
\text { ao ensino médio. }\end{array}$ & $\begin{array}{l}\text { Este trabalho visa, a partir da proposta de atividades } \\
\text { contextualizadas, apresentar uma dequência didática para } \\
\text { trabalhar o conteúdo de matrizes com alunos do Ensino Médio. }\end{array}$ \\
\hline A10 & $\begin{array}{l}\text { A contextualização de matrizes } \\
\text { no ensino médio: uma proposta } \\
\text { de trabalho. }\end{array}$ & $\begin{array}{l}\text { Apresentar abordagens diferenciadas no ensino de matrizes, } \\
\text { levando em consideração a contextualização do tema em assuntos } \\
\text { pertinentes para os alunos do ensino médio. }\end{array}$ \\
\hline A11 & $\begin{array}{l}\text { Modelagem matemática: Uma } \\
\text { abordagem do método gráfico e } \\
\text { do método simplex na resolução } \\
\text { de problemas de otimização. }\end{array}$ & $\begin{array}{l}\text { Escolher situações-problemas que envolvam problemas de } \\
\text { otimização e procurar resolvê-los através do Método Gráfico e do } \\
\text { Método Simplex. }\end{array}$ \\
\hline A12 & $\begin{array}{l}\text { O ensino e aprendizagem de } \\
\text { matrizes no contexto da } \\
\text { resolução de problemas e da } \\
\text { plataforma whatsapp. }\end{array}$ & $\begin{array}{l}\text { Discutir o estudo de Matrizes a partir da Resolução de } \\
\text { Problemas, utilizando como meio o whatsapp. }\end{array}$ \\
\hline
\end{tabular}

Analisando cada objetivo apresentado no Quadro 2, pode-se observar que as pesquisas identificadas por A4, A9 e A10, mencionam o termo contextualização já no objetivo da pesquisa, enquanto que as pesquisas identificadas por A1, A2, A3, A5, A6, A7, A8, A11 e A12 não mencionam o termo contextualização nos objetivos, mas mesmo assim é possível que exista a contextualização nos resultados, seja ela no contexto da matemática pura, da semi-realidade ou da realidade.

\section{b) Bases teóricas}

Nessa categoria apresentam-se as teorias base utilizadas em cada pesquisa analisada (Quadro 1). Para isso corrobora-se com Biembengut (2008), quando sublinha que o pesquisador deve obter um bom arcabouço teórico que represente a busca por uma vasta fonte de pesquisa. Isso é feito para fundamentar o seu trabalho e serve como base para as ideias defendidas no procedimento de análise. Assim analisando os referidos trabalhos apresentado no Quadro 1 constatou-se que as pesquisas identificadas por A1, A5, A6 e A12 utilizam as concepções propostas por Polya (1995), o qual aborda as fases da resolução de problemas como fundamentação teórica. A mesma associação acontece com as pesquisas A4, A8, A9, A10 onde foi percebida uma preocupação com o estudo da Matemática por meio de situações-problemas que permitem uma melhor contextualização e, consequentemente, maior proximidade com a realidade do estudante.

Na pesquisa A2 a autora realiza uma análise nos livros didáticos indicando que não se dá tanta importância para a contextualização do conteúdo, sendo focado mais na técnica de operações, ou seja, exercícios enfatizando a matemática pura (SKOVSMOSE, 2000). Segundo a autora, o livro didático disponível na escola, acessado por ela para a pesquisa, traz inicialmente a definição de Matrizes e logo em 
seguida alguns exemplos, não dando tanta importância para a contextualização do conteúdo.

Na pesquisa A3 o autor aborda o emprego de ferramentas sensoriamento remoto e processamento digital de imagens no ensino de matrizes com o Matlab. O autor apresenta uma abordagem mais prática com aplicações de matrizes utilizando o software Matlab, sem nenhuma situação problema ou contextualização do conteúdo. Assim como na pesquisa A7 e A11 que embora os autores tenham abordado o método de resolução de problemas no conteúdo de Matrizes, o que se observa são atividades mais voltadas para as técnicas e aplicações do conteúdo e contextualizadas apenas no contexto da matemática pura (SKOVSMOSE, 2000).

\section{c) Principais resultados}

Os resultados apresentados nesta seção são referentes à conclusão de cada autor(a) em cada uma das pesquisas analisadas de A1 até A12 e não se referem à interpretação das autoras desta pesquisa.

Na pesquisa A1, os estudantes tiveram a oportunidade de trabalhar o conteúdo de matrizes e determinantes com situações-problema envolvendo diversas informações do seu meio social, para depois serem transformados em conhecimentos matemáticos, possibilitando uma aprendizagem mais significativa ao invés da aprendizagem mecânica, desconectada da suas realidades. Em A2 a autora realizou uma análise de alguns livros didáticos e afirma que não há uma apresentação clara e organizada dos conceitos, os exercícios são repetitivos, levando o aluno apenas a seguir as técnicas. A autora afirma ainda que os livros falham em apresentar atividades investigativas e em grupos, sendo elas essenciais no desenvolvimento do raciocínio lógico e na criação de estratégias na resolução de problemas.

O trabalho A3 mostrou que o emprego do sensoramento remoto e do processamento digital de imagens, quando aplicado ao cálculo de matrizes, tende a despertar no aluno o gosto pelo processo de aprendizagem, pois não o afasta das tecnologias da informação. O trabalho mostrou que é possível dinamizar o processo de aprendizagem na Matemática, de modo a levar os estudantes à busca de novas descobertas; a testar parâmetros; a examinar de forma célere os conteúdos ministrados pelos professores; tudo isso com uso de diferentes tipos de softwares, como é o caso do MatLab. Para a autora da pesquisa A4 o ensino de matrizes utilizando a teoria dos 
grafos foi muito importante para o resultado dos alunos na realização das atividades propostas. Segundo a autora por meio do relato de experiência, foi possível verificar que o conhecimento matemático adquirido durante as atividades propostas contribuíram para o processo ensino e aprendizagem dos estudantes, pois propiciou-lhes uma melhor forma de estudar e interpretar uma situação problema.

Na pesquisa A5 o autor conclui que em relação a visão de mundo dos alunos, nos momentos em que se utilizam atividades com softwares e que se trabalha com a história em conexão com o mundo tecnológico atual, ficou clara a percepção que as matrizes ocupam lugar essencial no funcionamento dos vários equipamentos e softwares que eles próprios utilizam, isto os fez refletir sobre a importância que teve o desenvolvimento deste assunto, uma vez que conheceram a história. Segundo o autor de A6 um bom problema pode tornar as aulas de matemática mais interessantes e desafiadoras, pois proporcionam um maior envolvimento no processo e resolução, aguçando a criatividade e colaborando com o desenvolvimento de estratégias que possam ser aplicadas em diferentes situações. Percebe-se então a importância da resolução de problemas e das aplicações como metodologia para o ensino da Matemática.

Em A7 os alunos foram estimulados a utilizar a linguagem matemática para estruturar questões de seus interesses. Essas questões fizeram com que a Matemática apresentasse um sentido prático, visto que tudo o que foi proposto pertence ao universo real deles (contexto da realidade). Segundo a autora pode-se afirmar que, deste modo, a Matemática cumpre o seu papel, viabilizando análises e resoluções de problemas reais, levando os estudantes a desenvolverem novos saberes e aplicá-los a antigos questionamentos.

O autor de A8 conclui que o estudo da Matemática pode sim ser mais prazeroso e desafiante e, ainda propõem o uso da planilha eletrônica como uma alternativa eficaz no ensino de matrizes, determinantes e sistemas lineares. Para ele o trabalho com recursos computacionais na prática pedagógica contribuiu para a melhoria do entendimento do conteúdo, aumento da participação dos alunos durante as aulas, e no interesse dos mesmos pela Matemática. Com o trabalho realizado em A9 o autor conclui que a ideia de aprender Matemática de forma contextualizada possibilita o desenvolvimento da autonomia e da criatividade, sem dizer que uma pequena parcela dos livros didáticos trabalha este conceito de forma descontextualizada. 
$\mathrm{Na}$ conclusão da pesquisa A10 foi percebida uma preocupação com a contextualização do ensino, assim como com um ensino consistente e que trouxesse uma produção de significados para o aluno de forma que possa contribuir para seu aprendizado. A proposta de A11 em se resolver problemas de otimização por meio do Método Gráfico e pelo Método Simplex possibilitou ao estudante perceber que problemas que ocorrem na prática, em empresas, por exemplo, podem ser resolvidos muitas vezes com conhecimentos adquiridos no Ensino Médio.

A pesquisa A12 utiliza-se do aplicativo whatsapp como elemento de promoção de atitudes positivas nos alunos, pois estes demonstraram durante a pesquisa motivação na busca de elementos para o estudo de Matrizes. O método de resolução de problemas, a mídia e as sugestões no grupo virtual serviram como ponto de interesse para os alunos interagirem, logo acredita-se que os professores podem utilizar o aplicativo para que os alunos possam explorar o conhecimento matemático em sua própria aprendizagem.

Com a análise dos resultados observa-se que as pesquisas identificadas A4, A9, A10 e A12 dão ênfase em situações contextualizadas, enquanto que as pesquisas A1 e A5 não mencionam a contextualização nos objetivos, mas no desenvolver do trabalho, observa-se que a contextualização está presente. Já as pesquisas identificadas como A2, A3, A6, A7, A8 e A9 não mencionam o termo contextualização no objetivo e nem na análise dos resultados da pesquisa.

\section{d) Indícios de Contextualização de Matrizes}

Nas pesquisas identificadas como A2, A3, A6, A7, A8 e A11 foi observado uma abordagem mais técnica e voltada à aplicação direta das definições e propriedades das Matrizes, sempre procurando associar a teoria com situações problemas que remetam à prática. Geralmente são apresentados de modo artificial, satisfazendo apenas um vocabulário matemático, não contemplam a contextualização no objetivo nem nas análises dos resultados, estando no contexto da matemática pura, destacando-se pela aplicação prática das matrizes. Diante do exposto, corrobora-se com Fernandes (2006) quando o mesmo afirma que o ensino de Matemática, por vezes, apresenta-se de maneira descontextualizada (da realidade), carregado de atividades fora da vivência dos estudantes.

As pesquisas identificadas como A6, A8 e A11 utilizaram-se do método de resolução de problemas enquanto os autores das pesquisas A2, A3 e A7 utilizaram 
recursos computacionais, com intuito de motivar os estudantes no que tange o processo de ensino e de aprendizagem do conteúdo de Matrizes. Os autores consideraram o contexto da matemática pura ou da semi-realidade (SKOVSMOSE, 2000), ao aplicarem o conteúdo de Matrizes com situações-problema criadas que procuravam contemplar o “cotidiano" do estudante, sem sucesso. De acordo com Ricardo (2005), quando há uma tentativa de partir da realidade, mas não há um retorno a esta, o resultado é um conhecimento científico escolar sistematizado em situações didáticas artificiais (semirealidade).

É possível destacar que a contextualização como movimento desencadeado em uma proposta de ensino tem por objetivo fundamentar o processo de aprendizagem, possibilitando estabelecer sentido no aluno para os significados dos conceitos matemáticos, pois de acordo com a BNCC (BRASIL, 2018), um dos desafios para a aprendizagem da Matemática no Ensino Médio é exatamente proporcionar aos estudantes a visão de que ela não é um conjunto de regras e técnicas, mas faz parte da cultura e da história.

Dessa forma, nestas seis pesquisas mencionadas (A2, A3, A6, A7, A8 e A11), constatou-se que não há uma contextualização na realidade, mas sim um conjunto de aplicações de matrizes que podem até partir de uma (semi) realidade do estudante, mas não passam pelo processo de modelização ou modelagem, para retornar à tal realidade. Apresentam-se apenas como uma 'pseudocontextualização' (CONCEIÇÃO; JESUS; MADRUGA, 2018), ou seja, reduz a contextualização a uma "descida do abstrato para o concreto servindo mais como ilustração do que instrumento de compreensão do mundo" (RICARDO, 2005, p. 239). Essas 'aplicações' talvez não contemplem integralmente o processo formativo do estudante no que tange a aprendizagem de matrizes.

Já as pesquisas identificadas como A4, A9, A10 e A12 abordam um conteúdo de Matrizes aparentemente contextualizado na realidade, mencionando o termo contextualização no objetivo e também nas análises dos resultados. Estas pesquisas buscaram alternativas para tornar as aulas mais dinâmicas, atraentes e produtiva, possibilitando uma aprendizagem mais significativa, pois "é na dinâmica de contextualização e descontextualização que o aluno constrói conhecimento com significado" (BRASIL, 2006, p.83), possibilitando o desenvolvimento da autonomia e da criatividade fazendo com que o estudante possa ver sua utilidade. 
Nas pesquisas A1 e A5 os autores não tratam de contextualização no objetivo, mas no desenvolvimento dos procedimentos metodológicos destas pesquisas a contextualização se faz presente. Os autores utilizam-se de situações problemas conforme as concepções de Polya (1995), deixando evidente que se utilizam da contextualização, mesmo que de forma implícita. De acordo com Tufano (2001, p. 41), “a contextualização é um ato particular. Cada autor, escritor, pesquisador ou professor contextualiza de acordo com suas origens, com suas raízes, com seu modo de ver as coisas com muita prudência".

Foi possível perceber nestes trabalhos que há relação com o cotidiano e com a formação do sujeito, ou seja, partir do contexto da realidade do estudante (SKOVSMOSE, 2000), e há um movimento de volta à essa realidade, porém com um novo olhar, com chances de percepção e ação, dispondo de ferramentas intelectuais para tal (RICARDO, 2005). E ainda “[...] que há uma construção de significado, situações que instigam o conhecimento matemático do estudante para além da sala de aula" (CONCEIÇÃO; JESUS; MADRUGA, 2018, p. 305).

Os autores trabalharam com a teoria e prática, sempre buscando interagir com o contexto real, para que o estudante estimule novas ideias e promova uma visão estruturada, que inclui relações abstratas de algum fenômeno e ainda compreendê-lo. "A contextualização, nesse caso, completa-se no momento em que se parte da realidade e a ela retorna, mas com um novo olhar, com possibilidades de compreensão e ação, pois agora se dispõe de ferramentas intelectuais para tal"' (RICARDO, 2005, p. 239).

Uma das maneiras de contemplar este processo defendido por Ricardo (2005) é por meio da modelagem matemática, que, dentre suas diversas concepções, pode auxiliar na contextualização de matrizes e também outros conteúdos matemáticos, no que tange ao contexto da realidade. De acordo com Bassanezi (2010), a modelagem é o processo de criação de modelos onde estão definidas as estratégias de ação do indivíduo sobre a realidade, mais especificamente, sobre a sua realidade, carregada de interpretações e subjetividades.

De acordo com Bassanezi (2010), a modelagem matemática faz uma ligação entre as representações e o mundo. O autor a define como um processo dinâmico, utilizado para obter e validar modelos (matemáticos). Ele a considera uma forma de abstração e generalização com intuito de prever tendências. - "A modelagem consiste, essencialmente, na arte de transformar situações da realidade em problemas 
matemáticos cujas soluções devem ser interpretadas na linguagem usual"

(BASSANEZI, 2010, p. 24). Bassanezi (2010) também afirma que o benefício da modelagem matemática é possibilitar, por meio de cálculos, validar o modelo, efetuar previsões sobre o comportamento do sistema e tentar controlá-lo. Uma vez que o processo permite uma aproximação da realidade, pode ser uma forma eficaz de contextualizar conteúdos matemáticos e facilitar a aprendizagem dos estudantes.

O uso da contextualização na realidade (por meio ou não da modelagem) como forma de potencializar o ensino de Matrizes, poderá desenvolver aspectos cognitivos dos estudantes, aprimorando seu senso de investigação, transformando os estudantes em sujeitos da própria aprendizagem sendo uma ferramenta essencial para o ensino e para a aprendizagem de Matemática, especificamente de Matrizes.

\section{CONSIDERAÇÕES FINAIS}

Este estudo teve como objetivo analisar como as pesquisas em ensino de Matemática desenvolvem a contextualização do conteúdo de Matrizes para estimular a aprendizagem de estudante no Ensino Médio. Para tanto, realizou-se um mapeamento das principais pesquisas disponíveis nos bancos de dados oficiais CAPES e BDTD, com a finalidade de encontrar trabalhos que abordassem o tema em questão e proporcionassem a análise dos dados das principais características individuais e comuns das pesquisas. Com as análises prévias, verificou-se algumas particularidades da situação atual do Ensino de Matrizes, visto que a abordagem do conteúdo é mais centrada nas técnicas, nas aplicações e pouco contextualizado na realidade, no entanto, há contextualização no contexto da semi-realidade e da matemática pura (SKOVSMOSE, 2000).

Dessa forma, respondendo à questão de pesquisas como as pesquisas em ensino de Matemática apresentam a contextualização do conteúdo de Matrizes para estimular a aprendizagem de estudantes do Ensino Médio? Pode-se observar que as pesquisas analisadas apresentam a contextualização para estimular a aprendizagem de estudantes de Ensino Médio no que tange ao conteúdo de matrizes, mas diferem quanto ao contexto apresentado, onde algumas pesquisas contextualizam na realidade, outras utilizam-se da semi-realidade e algumas apresentam apenas o contexto da matemática pura. 
Verificou-se que as pesquisas analisadas apresentam-se com inclinações para duas principais direções: 1) Aplicações - onde considerou-se que ocorreu uma "pseudocontextualização", ou seja, houveram aplicações com base na realidade sem um retorno à esta realidade (sem nenhuma modelização ou modelagem), pode-se dizer que houve contextualização na semi-realidade ou na matemática pura; e 2) Contextualização - onde considerou-se que houve a contextualização na realidade, conforme entendimento das autoras desta pesquisa, onde partiu-se da realidade e retornou-se a mesma - neste caso utilizando-se da modelização (ou modelagem, mesmo que de forma implícita).

No decorrer da elaboração deste trabalho, por meio dos estudos teóricos e da análise das pesquisas selecionadas, foi possível perceber que a contextualização é uma estratégia que poderá auxiliar o professor na tarefa de ensinar Matemática, e os estudantes no desafio de aprender. Acredita-se que quando se contextualiza um conteúdo matemático na realidade, como Matrizes, por exemplo, possibilita uma maior compreensão por parte dos estudantes e assim contribui com o processo de ensino e de aprendizagem da Matemática.

De acordo com o exposto, é possível que a contextualização na realidade, como recurso pedagógico, possa tornar a aprendizagem com mais significado, ao associá-la com experiências da vida cotidiana e realidade dos estudantes. Para tanto, pode-se sugerir a modelagem matemática como um caminho para potencializar o ensino por meio da contextualização na realidade dos diferentes conteúdos matemáticos, e consequentemente facilitar a aprendizagem dos estudantes.

\section{REFERÊNCIAS}

BARBOSA, J. C. A "contextualização" e a Modelagem na educação matemática do ensino médio. In: ENCONTRO NACIONAL DE EDUCAÇÃO MATEMÁTICA, 8., 2004, Recife. Anais... Recife: SBEM, 2004. 1 CD-ROM.

BASSANEZI, R. C. Ensino-aprendizagem com Modelagem Matemática. São Paulo: Contexto. 2010.

BIEMBENGUT, M. S. Mapeamento na Pesquisa Educacional. Rio de Janeiro: Editora Ciência Moderna, 2008.

BRASIL, Ministério da Educação, Secretaria de Educação Básica. Base Nacional Comum Curricular - Ensino Médio. Disponível em: 
http://portal.mec.gov.br/index.php?option=com_docman\&view=download\&alias $=8512$ 1 -bncc-ensino-medio\&category_slug=abril-2018-pdf\&Itemid=30192. Acesso em $30 \mathrm{de}$ julho de 2019.

BRASIL, Ministério da Educação, Secretaria de Educação Básica. Orientações curriculares para o Ensino Médio: Ciências da natureza, matemática e suas tecnologias. Brasília: Secretaria de Educação Básica, 2006. Disponível em: <http://portal.mec.gov.br/seb/arquivos/pdf/book volume 02 internet.pdf > . Acesso em 07 de novembro de 2018.

CONCEIÇÃO, J. S.; JESUS, G. B.; MADRUGA, Z. E. F. Contextualização no Ensino de Matemática: concepções de futuros professores. Revista REAMEC, Cuiabá - MT, v. 6, n. 2, jul/dez 2018.

FERREIRA, A. B. d. H. Minidicionário Aurélio. Rio de Janeiro: Nova Fronteiro, 1992.

FERNANDES, S. S. A contextualização no ensino de Matemática - um estudo com alunos e professores do ensino fundamental da rede particular de ensino do Distrito Federal. 2006. Trabalho Monográfico (graduação) - Universidade Católica de Brasília, Brasília, 2006. Disponível em:

〈http://www.ucb.br/sites/100/103/TCC/22006/SusanadaSilvaFernandes.pdf>. Acesso em: 24 de novembro de 2018.

KATO, D. S. O significado pedagógico da contextualização para o ensino de ciências: análise dos documentos curriculares oficiais e de professores. 2007 Dissertação (Mestrado - Programa de Pós-graduação em Educação, área de concentração: Ensino de Ciências e Matemática) - Faculdade de Educação da Universidade de São Paulo.

MADRUGA, Z. E. F.; BREDA, A. Mapeamento de produções recentes sobre Modelagem Matemática nos anos iniciais. REMAT: Revista Eletrônica da Matemática, v. 3, n. 1, p. 67-81, 22 jul. 2017.

MAIOLI, M. A contextualização na matemática do Ensino Médio. Tese (Doutorado em Educação Matemática). São Paulo, Pontifícia Universidade Católica de São Paulo, 2012. Disponível em https://www.sapientia.pucsp.br/bitstream/handle/10922/1/Marcia\%20Maioli.pdf Acesso em 19 de junho de 2020.

MARCONI, M. A; LAKATOS, E. M. Fundamentos da Metodologia Científica. São Paulo: Editora Atlas, 2003.

POLYA, G. A arte de resolver problemas: um novo aspecto do método matemático /G. Polya; tradução e adaptação Heitor Lisboa de Araújo. - 2. reimpr. - Rio de Janeiro: interciência, 1995.

RICARDO, E. C. Competências, interdisciplinaridade e contextualização: dos Parâmetros Curriculares Nacionais a uma compreensão para o ensino das 
Ciências. Tese (Doutorado em Educação Científica e Tecnológica). Florianópolis, Universidade Federal de Santa Catarina. 2005. Disponível em:

$\leq$ https://repositorio.ufsc.br/bitstream/handle/123456789/102668/222646.pdf?sequence=1\&isAll owed=y $>$. Acesso em 27 de novembro de 2018.

SKOVSMOSE, O. Cenários de investigação. Bolema - Boletim de Educação Matemática, Rio Claro, n. 14, p. 66-91, 2000.

SKOVSMOSE, O. O que poderia significar a Educação Matemática Crítica para diferentes grupos de estudantes? Revista Paranaense de Educação Matemática, v.6, n.12, p.18-37, jul.-dez. 2017.

TUFANO, W. Contextualização. ln: FAZENDA, I. C. Dicionário em Construção: Interdisciplinaridade. São Paulo: Cortez, 2001

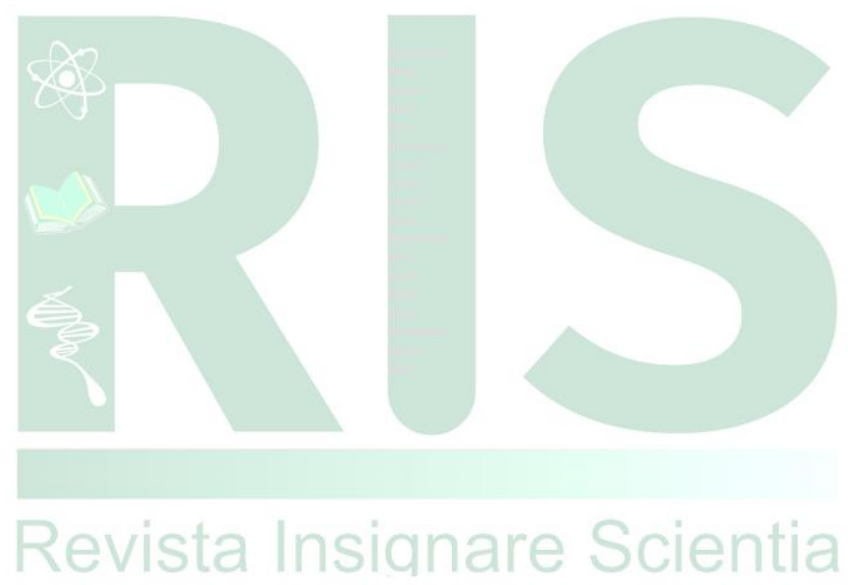

